\title{
Impact of Coronavirus Disease 2019 on Snail's Density of Schistosoma's Host in Wuhan
}

\section{Guangming LI}

Wuhan University

Dandan XU

Wuhan Centers for Disease Prevention and Control

Yanfang HU

Wuhan Centers for Disease Prevention and Control

Mingxing XU

Wuhan Centers for Disease Prevention and Control

Longjiang ZHANG

Wuhan University

Xiaoan DU

Wuhan University

Ling ZHANG

Wuhan University

Chao SUN

Wuhan University

Yaofei XIE

Wuhan University

Xiaodong Tan ( $00300469 @ w h u . e d u . c n$ )

Wuhan University https://orcid.org/0000-0002-8190-6060

\section{Research Article}

Keywords: Coronavirus disease 2019, schistosomiasis, snail’s density, Wuhan

Posted Date: April 5th, 2021

DOI: https://doi.org/10.21203/rs.3.rs-332620/v1

License: (1) This work is licensed under a Creative Commons Attribution 4.0 International License. Read Full License 
Impact of Coronavirus disease 2019 on snail`s density of Schistosoma`s

host in Wuhan

\title{
Guangming $\mathrm{LI}^{1}{ }^{1}$, Dandan $\mathrm{XU}^{2}{ }^{2}$, Yanfang $\mathrm{HU}^{3}$, Mingxing $\mathrm{XU}^{4}$, Longjiang ZHANG $^{1}$, Xiaoan DU ${ }^{1}$, Ling ZHANG ${ }^{1}$, Chao SUN ${ }^{1}$, Yaofei XIE ${ }^{1}$, Xiaodong TAN ${ }^{*}$
}

*Correspondence: 00300469@whu.edu.cn

+ Guangming LI and Dandan XU contributed equally to this work.

\begin{abstract}
Background:

The density of snails among schistosomiasis hosts has been kept at a low level and even disappeared in many places in Wuhan. However, from the beginning of the epidemic to the lifting of the seal in Wuhan, which the work of snail detection and extermination has been at a standstill. In order to analyze the potential harm of Coronavirus disease 2019 (COVID-19) on urban schistosomiasis transmission, we investigated the density of snails in the Jiangan and Hongshan districts of Wuhan, which evaluated the possibility of schistosomiasis outbreak in Wuhan city.
\end{abstract}

Methods: The density and infection status of snails were monitored by GPS satellite, which the risk value was calculated by adjusting Kaiser model. SigmaPlot was used to draw a three-dimensional risk matrix.

Results: (i)The living snail frame occurrence rate was $1.48 \%$ and the average living snail density was $0.054 / 0.11 \mathrm{~m}^{2}$ in 2020 . Compared with that in 2019 , the area of existing snails Tianxingzhou increased greatly. The area of historical snails was 24187 $\mathrm{m}^{2}$ has increased which the average density of living snails was $0.019 / 0.11 \mathrm{~m}^{2}$. No infectious snails were found in the survey area. (ii) Experts have high enthusiasm $(\mathrm{E}=100 \%)$. The authority of experts on the indicators of possibility, harmfulness and uncontrollability is $0.842,0.870$ and 0.866 respectively, all greater than 0.7 , indicating that expert evaluation is authoritative. After adjusting the Kaiser model, the top three risk values were the north bank of Tianxingzhou, Tianxingzhou as a whole, and Hongshan as a whole. The existing snail sites in the north bank of Tianxingzhou had the highest risk value and ranked the second Pak sha Chau. The highest risk value was 
found in the historical snail village of Yangsiji village. The risk events on the north bank of Tianxingzhou are located in the orange zone, which belongs to the high-risk area. The whole Hongshan District, the existing snail Tianxingzhou and the tail of Tianxingzhou are located in the yellow zone, belonging to the moderate risk area. Other risk events are located in the blue or green zones and are in the low risk or negligible sub-zone. (iii)The three dimensional risk matrix shows that the potential risk level of the existing snail spot and the possibility of risk occurrence of Tianxingzhou is high. The existing snail points on the Pak sha Chau, indicating the severity of the risk event; Historical snails, indicating the unpredictability of risk events once they occur. The emergency monitoring points show that once the risk event occurs, the level of uncontrollability rises instantly. The whole Hongshan district indicates the severity of the occurrence of the risk event.

Conclusion: Under the influence of Covid-19 epidemic, the risk of schistosomiasis infection was high and the historical snail snail appeared again in Wuhan. Therefore, the prevention and control work of schistosomiasis infection should be strengthened in Wuhan.

Key Words: Coronavirus disease 2019, schistosomiasis, snail`s density, Wuhan

\section{Introduction:}

Schistosomiasis is an infectious disease caused by human infection with Schistosoma[1]. It is estimated that at least 229 million people worldwide received treatment for schistosomiasis in 2018, with Africa as the region with the highest incidence[2]. They are mainly divided into schistosoma mansoni, schistosoma haematobium, schistosoma japonicum, embedded schistosoma, schistosoma Mekong and schistosoma Guinea, which Schistosoma mansoni, schistosoma haematobium and Schistosoma japonicum have the highest infection rate in China, it's mostly Schistosoma japonicum[3, 4]. There are two main ways of human infection with schistosomiasis: contact with water containing schistosome cercariae or contact with feces contaminated with schistosome. When the schistosome encounters the intermediate host snail, it propagates in large numbers in the body of the snail. The 
cercariae leave the snail and float on the surface of the water body. When the human contacts the water body, the cercariae enter the human body through the skin and turn into juveniles. After parasitizing in the human body for a certain period of time, it develops into adults and finally invades the human body[5]. When the human body comes into contact with the feces contaminated by schistosoma, the cercariae released in the feces will enter the human body through the broken skin and cause harm to the human body. People infected with schistosomiasis, faeces containing cercariae, released into the water, encounter snails of the intermediate host, can cause a new infection. snails play an important role in the spread of schistosomiasis[6].

Wuhan, Hubei Province is one of the most important epidemic areas of schistosomiasis in China[7]. Wuhan city is located in the Yangtze River Basin, which belongs to the subtropical monsoon humid area. It has a wide range of jurisdiction, rich water system, warm and humid climate, which makes some water systems form a favorable environment for snail breeding $[8,9]$. In the middle of August 1989, the acute schistosomiasis infection of nearly three thousands persons broke out in Yangyuan Street of Wuhan City[10], causing the loss of life and property of the large working people. For this reason, Jiang Zemin of the president of the People's Republic of China, gave orders to do a good job in the mass treatment. From 1991 to 2000, a small outbreak of schistosomiasis occurred in the urban center of Wuhan[11]. Among them, more than 200 cases were infected in 1991. In 1997, residents from Non-schistosomiasis endemic areas came to Zuoling town, Hongshan district, Wuhan city to be infected with schistosomiasis [10]. This incident has aroused great attention of urban managers, and proposed to strengthen the prevention and control of schistosomiasis in urban centers. In September 2004, four confirmed cases of acute schistosomiasis infection occurred in Houhu town, Jiangan district, Wuhan city[12], and other schistosomiasis infections were successively found through screening . Throughout the development road of Wuhan city can be found, because of its special geographical location, which has been is in the process of struggle with schistosomiasis. Although great progress was made in schistosomiasis control work in recent years, not the outbreak of acute schistosomiasis, but Wuhan city is consistent on the verge of risk of schistosomiasis infection. Because 
of the influence of the snails breeding and flood disasters, Wuhan city outbreak of schistosomiasis may at any time.

After the outbreak of novel coronavirus (COVID-19) in Wuhan, China in 2020[13], Wuhan quickly took the city closure on January 23[14], until April 8, during the control of schistosomiasis in Wuhan was almost stopped. The snail inspection and extermination work that should have been carried out in spring (January to March) was not carried out, which exposed urban residents in Wuhan to a great risk of schistosomiasis infection. In the summer, Wuhan will usher in the worst rainfall in a hundred years, which will make the water level of Wuhan section of the Yangtze River soar in 2020. The Yangtze River beach in Wuhan will be invaded by the epidemic water for a long time, which will greatly increase the chances of Wuhan urban residents contacting the epidemic water. There has always been a distribution of snails growing in the intermediate host of Schistosoma in Wuhan city. Schistosomiasis mainly invades the human body through the cercaria released in the water by the intermediate host snails, causing acute or chronic infection of schistosomiasis[15]. During the COVID19 epidemic period, the breeding density of migratory snails may greatly increase and the activities may further expand with time due to the failure of snail killing in time 。 The possibility of water contamination by snail cercariae released by snails is greatly increased. Therefore, the risk of schistosomiasis after COVID-19 may increase significantly.

As a classical method of expert evaluation, Delphi method is widely used. According to the value of expert evaluation, quickly form the evaluation results, for the medical field or public health to provide impartial, objective and professional reference $[16,17]$. Kaiser model is a disaster vulnerability analysis tool developed by some emergency management departments and research institutions in the United States, but it has been used for reference in medical research in recent years to evaluate the possibility of risk events, and has been recognized by experts in the field of public health with its efficient and rapid efficiency [18]. The risk matrix method is used as the risk grade identification methodology[19].

In november 2020 winter, Wuhan mainly monitored the distribution of snails in 
Jiangan district and Hongshan district. The average density of snails in Jiangan district $\left(0.019 / 0.11 \mathrm{~m}^{2}\right)$ increased by $21.79 \%$ compared with that in 2019 , and that in Hongshan district $\left(0.054 / 0.11 \mathrm{~m}^{2}\right)$ increased by $980 \%$ compared with that in 2019 . The average density of snails in Hongshan district was high and fast growing. In order to explore the risk and severity of schistosomiasis in Wuhan city, the snail situation in Hongshan district was taken as the representative of the overall situation of schistosomiasis in Wuhan city. The risk matrix evaluation method was used to carry out the risk assessment of schistosomiasis infection in Wuhan city, and the quantitative research method was used to classify the risk level of schistosomiasis infection to provide reference for risk early warning and emergency response.

\section{Methods and Materials :}

1.1 Snail monitoring: According to the data of schistosomiasis surveillance over the years in Wuhan City, the surveillance areas were divided into existing snail sites, historical snail sites and emergency snail sites. By using handheld GPS, Basecamp and Google Earth software, the snail distribution and range of three snail points were investigated, and the spatial distribution of snails was visually displayed on the map [20,21].

1.2 Survey of crowd activity characteristics:

According to the government demographic data, field survey and historical data analysis, the population distribution characteristics are divided into five levels( 0 $\sim 10,10 \sim 50,50 \sim 100,100 \sim 200,>200$ person / day).

\subsection{Expert consultation Method}

12 experts in the comprehensive field of schistosomiasis control and prevention were invited to attend the video conferencing. They were from teaching and scientific research, Centers for Disease Control and Prevention and health administration. To provide the experts with the snail monitoring results and social behavior characteristics of the population in Wuhan city the experts use their relevant knowledge and experience to score different assessment indicators, and finally form the results of risk assessment $[22,23]$.

1.4 Methods for evaluation of consultation results 


\subsubsection{Positive coefficient and authority degree of Expert}

The questionnaire recovery rate was used to represent the positive coefficient (E) of experts to evaluate the positive degree and participation degree of experts in project consultation. $E=N_{i} / N$, Where $\mathrm{N}$ represents the number of experts consulted and $N_{i}$ represents the number of experts actually recovered. The expert authority degree $\mathrm{Cr}$, which represents the arithmetic mean of the proficiency degree $\left(C_{\alpha}\right)$ and the expert judgment basis $\left(C_{\beta}\right)$, evaluates the expert's understanding of the field and the credibility and reliability of the expert consultation results [24]. The range of $\mathrm{Cr}$ is $0 \sim 0.95$, and the critical value of credibility is $\mathrm{Cr} \geq 0.7, \mathrm{Cr}=\frac{\left(C_{\alpha}+C_{\beta}\right)}{2}$. According to Likert's five level scoring method, the proficiency of the indicators ranged from very familiar to very unfamiliar, with a value of 1.0-0.2. The judgment basis is divided into theoretical analysis $(0.3,0.2,0.1)$, practical experience $(0.5,0.4,0.3)$, reference to foreign scholars' works $(0.1,0.08,0.06)$, intuition $(0.1,0.08,0.06)$, and the judgment basis is divided into large, medium and small according to the degree of influence on experts.

\subsubsection{Adjustment Kaiser model:}

Based on the Kaiser model and the results of the expert meeting, a risk assessment system for schistosomiasis infection in Wuhan city was established. The index of harmfulness and non-hollowness is weighted by experts $\left(w_{i}\right)$. Weighted average $\overline{\omega_{J=1}^{m}}=\frac{1}{n} \sum_{i=1}^{n} w_{i}$, Where $j$ stands for indicator $j, \mathrm{~m}$ for the number of indicators ( $\mathrm{m}$ $=2), i$ for the number of experts, $\mathrm{n}$ for the number of experts. The relative risk was calculated using the Kaiser tool table calculation formula [25].Relative risk（Risk\%) $=($ Possibility $/ 3) *\left(\right.$ Population health impact score* $w_{1}+$ Impact on production and life of local residents $* w_{1}+$ Increase capital investment* $w_{1}+$ Influence of public opinion* $w_{1}+$ Emergency Preparedness $* w_{2}+$ Internal response $* w_{2}+$ Implementation of prevention and control policies $\left.* w_{2}\right) / 6 * 100 \%$

\subsubsection{Risk Matrix}

According to the probability of occurrence and severity of risk events (harmfulness and uncontrollabillity) determined by experts, quantitative scores are 
made. In this study, the two-dimensional risk matrix values are converted and the twodimensional risk matrix is drawn according to the scoring values of the risk assessment system (0 3). The risk level is divided into five levels: negligible risk, low risk, moderate risk, high risk and extremely high risk. The corresponding risk levels of blue, green, yellow, orange and red increase in turn. According to the possibility, harmfulness and uncontrollability of the expert score, the three-dimensional risk matrix is drawn.

\subsection{Data Analysis}

Google Earth was used to import GPX files and draw KMZ information snail situation map. Using Excel software, input and sort out expert evaluation data, and conduct general descriptive analysis. According to the Excel tool table of Kaiser model, the improved risk value calculation was carried out. Sigmaplot12.5 was used to draw a three-dimensional risk matrix.

\section{Results}

1. Snail monitoring results in Wuhan in 2020

The results showed that there were a total area of 2,259,955 m2, 290 snail frames, and the occurrence rate of snail frames was $1.70 \%$. A total of 1025 snails were captured and 1025 snails were dissected, among which 924 snails were captured, 253 snail frames were dissected, the occurrence rate of snail frames was $1.48 \%$, and the average density of living snails was $0.054 / 0.11 \mathrm{~m} 2$. No snails were found in the emergency monitoring points. No infectious snails were found in the survey area (Figure 1). Comparison of snail situation in WuHan City from 2018 to 2020(see additional files 1).

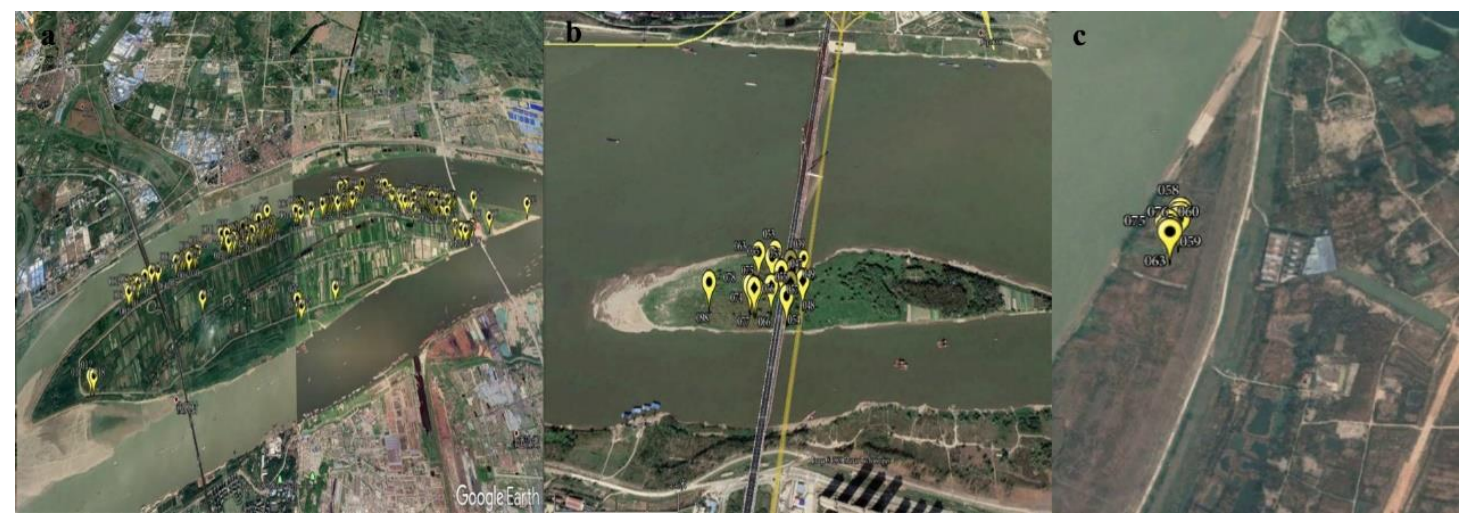

Figure1 Distribution of snails in Wuhan city in 2020. a:express Tianxingzhou, 
b:express Pak sha Chau, c:express Yangsi Ji village

2.Distribution of population characteristics

Existing snails point Tianxingzhou, Pak Sha Chau, historical snail point villages, emergency monitoring snail point Qingling River crowd activities(see additional files 2). The population characteristic distribution and the snail spot superposition chart (Figure2) showed that the existing areas with high snail spot population activity were consistent with the snail spot distribution.

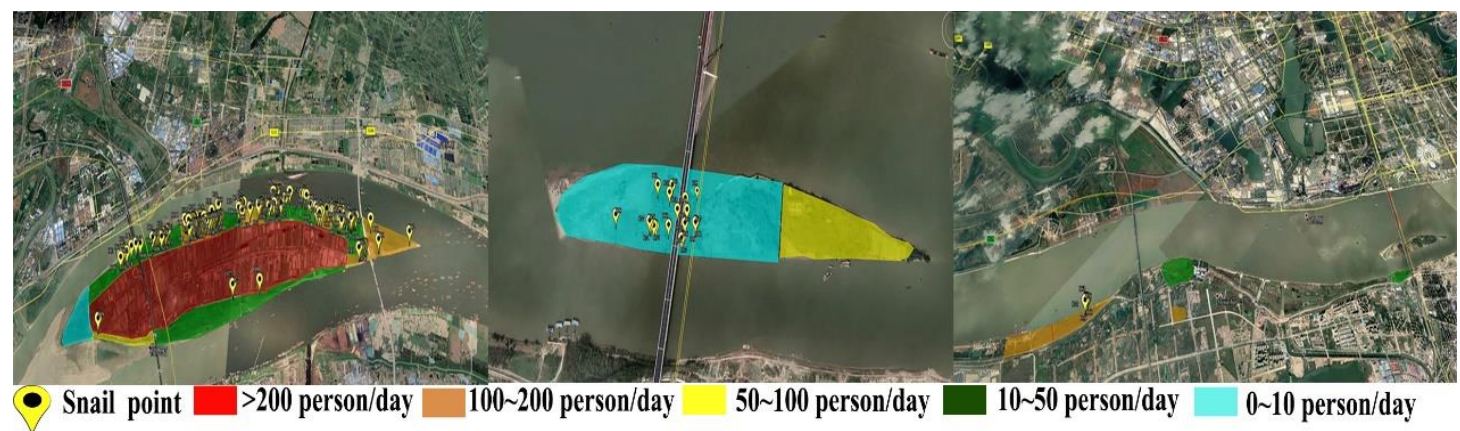

Figure 2 Schematic diagram of population characteristic distribution and snail point superposition. a:express Tianxingzhou, b:express Pak sha Chau, c:express Yangsi Ji village

\section{Basic information of experts}

The experts invited in our expert consultation included 8 male $(66.67 \%)$ and 4 female (33.33\%), 4 were Senior experts(33.33\%) and 5 were Deputy Senior(41.68\%). The experts had participated in schistosomiasis control for an average period of $20.92 \pm 12.28$ years. Moreover, 8 experts had worked in schistosomiasis control for over 15 years (Table 3 ).

Table 3. Basic information of experts

\begin{tabular}{llll}
\hline Variables & Category & $\mathrm{n}$ & $\%$ \\
\hline Sex & Male & 8 & 66.67 \\
& Female & 4 & 33.33 \\
Age(year) & $30 \sim 40$ & 3 & 25 \\
\hline
\end{tabular}




\begin{tabular}{|c|c|c|c|}
\hline & $40 \sim 50$ & 3 & 25 \\
\hline & $50 \sim 60$ & 6 & 50 \\
\hline \multirow[t]{3}{*}{ Highest education } & Doctor's degree & 2 & 17 \\
\hline & Master's degree & 4 & 33 \\
\hline & Bachelor's degree & 6 & 50 \\
\hline \multirow{6}{*}{$\begin{array}{l}\text { Professional and Technical } \\
\text { Title }\end{array}$} & Senior & 4 & 33.33 \\
\hline & & & \\
\hline & Deputy Senior & 5 & 41.68 \\
\hline & Intermediate & 1 & 8.33 \\
\hline & Primary & 1 & 8.33 \\
\hline & No title & 1 & 8.33 \\
\hline \multirow{3}{*}{$\begin{array}{l}\text { Years of working } \\
\text { schistosomiasis control }\end{array}$} & $<15$ & 4 & 33.33 \\
\hline & $15 \sim 30$ & 3 & 25 \\
\hline & $\geq 30$ & 5 & 41.67 \\
\hline
\end{tabular}




\section{Construction of expert index system}

According to the characteristics of schistosomiasis control in Wuhan City, a personalized evaluation index system was established (See additional files 3).

5. Expert enthusiasm and authority

According to the evaluation, 12 questionnaires were sent out ,which 12 questionaires were recovered, with a recovery rate of $100 \%$. The experts were highly motivated. The authority of experts on the indicators of possibility, harm, and uncontrollability is $0.842,0.870,0.866$ respectively, which are all greater than 0.7 , indicating that the expert's evaluation of each indicator is credible and reliable (Table 5).

Table5 Expert authoritative results

\begin{tabular}{lccc}
\hline & Basis of & Proficiency $\left(C_{\beta}\right)$ & $\mathrm{Cr}$ \\
\hline Possibility & 0.817 & 0.867 & 0.842 \\
Harmfulness & 0.873 & 0.867 & 0.87 \\
Uncontrollability & 0.865 & 0.867 & 0.866 \\
\hline
\end{tabular}

6. The risk value of the adjust Kasier model

The riskiest three places were the outer north bank of Tianxingzhou dike, the whole of Tianxingzhou and the whole of Hongshan district. The north bank outside Tianxingzhou polder had the highest risk value and Pak Sha Chau on existing snail had the second highest risk value. The highest risk value was found in Yangsiji village, a historical snail location. The risk value of emergency monitoring snails was very low. (See additional files 4)

7. Results of two-dimensional risk matrix 
The risk events on the north bank of Tianxingzhou are located in the orange zone, which belongs to the high-risk area. The whole Hongshan District, the existing snail Tianxingzhou and the end of the continent of Tianxingzhou are located in the yellow zone, belonging to the moderate risk area.Other risk events are located in the blue or green zones and are in the low risk or negligible sub-zone(Figure 3).

\begin{tabular}{|c|c|c|c|c|c|c|}
\hline \multirow{5}{*}{$\begin{array}{l}\text { Possibil } \\
\text { ity }\end{array}$} & $\begin{array}{l}\text { Inevitable } \\
(2.4 \sim)\end{array}$ & & & & & \\
\hline & $\begin{array}{c}\text { Very possible } \\
(1.8 \sim)\end{array}$ & & & D1 & & \\
\hline & $\begin{array}{l}\text { Possible } \\
(1.2 \sim)\end{array}$ & & & $\mathrm{A} / \mathrm{B} / \mathrm{C} 1 /$ & & \\
\hline & $\begin{array}{l}\text { Unlikely } \\
(0.6 \sim)\end{array}$ & & & $\begin{array}{c}\mathrm{C} / \mathrm{D} / \mathrm{A} 1 / \mathrm{B} \\
1 / \mathrm{E} 1 / \mathrm{F} 1 / \mathrm{C} \\
2\end{array}$ & & \\
\hline & $\begin{array}{l}\text { Rare } \\
(0 \sim)\end{array}$ & & E/A3 & $\begin{array}{l}\mathrm{A} 2 / \mathrm{B} 2 / \mathrm{D} 2 \\
/ \mathrm{E} 2 / \mathrm{F} 2 / \mathrm{G} 2\end{array}$ & & \\
\hline \multirow{2}{*}{\multicolumn{2}{|c|}{$\begin{array}{c}\text { Two Dimensional Risk } \\
\text { Matrix }\end{array}$}} & $\begin{array}{l}\text { Negligible } \\
\quad(0 \sim)\end{array}$ & $\begin{array}{r}\text { Low risk } \\
(0.6 \sim)\end{array}$ & $\begin{array}{l}\text { Moderate } \\
(1.2 \sim)\end{array}$ & $\begin{array}{c}\text { Serious } \\
(1.8 \sim)\end{array}$ & $\begin{array}{c}\text { Very serious } \\
(2.4 \sim)\end{array}$ \\
\hline & & \multicolumn{5}{|c|}{ Severity } \\
\hline
\end{tabular}

Figure3 Two-dimensional risk matrix diagram of schistosoma control risk events in Hongshan district

Note: $A=$ Hongshan District , B=Existing Snail-Tian xing Zhou, C=Existing Snail-Pak sha Chau, D=Historical, E=Emergency Monitoring Point, A1=Tian xing Zhou-Chau head, B1=Tian xing Zhou-Middle of the continent, C1=Tian xing Zhou-End of the continent, D1=Tian xing Zhou-North Shore, E1=Tian xing Zhou-South Bank, F1=Pak sha Chau, A2=HengDi Village, B2=Rocket Village, C2=Yangsiji Village, D2=Shizui Village, E2=Xiwan Village, F2=Jianhe Village, G2=Changjiang Village, A3= Qingling River.

8. Three dimensional risk matrix

The three-dimensional matrix of the existing snail point Tianxingzhou fluctuates greatly, and the corresponding uncontrollability is relatively large at the point with the greatest possibility and harmfulness, but the corresponding maximum possibility is at the point with the least uncontrollability and harmfulness, which indicates that the 
potential risk level of TianXingzhou is high, and the possibility of risk occurrence is very high. The existing snails point in Pak Sha Chau is the least harmful and the corresponding risk events are most likely to occur and uncontrollable, indicating the seriousness of the risk events. The historical snails point, the downward fluctuation of the three-dimensional matrix, indicates that the occurrence of the risk event is low, the risk event is the most harmful and the possibility is moderate, and the occurrence of the risk event is the most uncontrollable, indicating the unpredictability of the risk event once it occurs. The uncontrollability of emergency monitoring points increases gradually with the increase of hazard. With the increase of possibility, the uncontrollability level first increases and then decreases, which indicates that once the risk event occurs, the uncontrollability level increases instantaneously. The overall three-dimensional matrix of Hongshan district fluctuates little, but in the minimum hazard, the corresponding risk events have the greatest possibility and uncontrollability, indicating the severity of risk events. The results of three-dimensional matrix are consistent with the results of two-dimensional risk matrix, which proves the possibility of risk events from the perspective of quantitative and qualitative (Figure 4). 


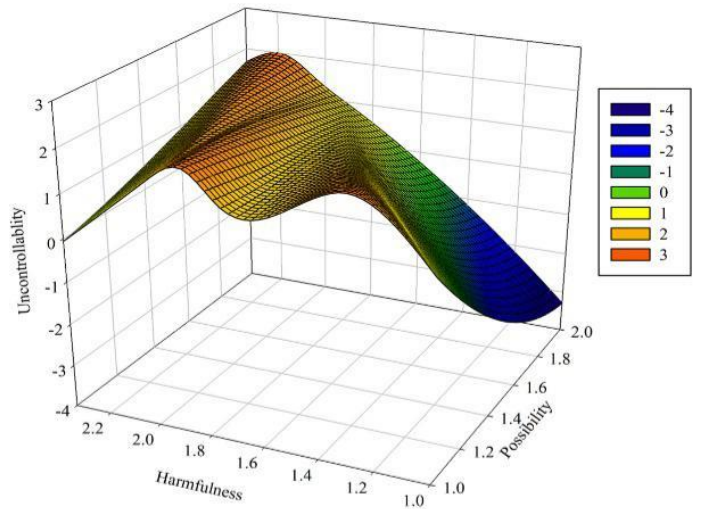

a: Existing Snail-Tianxing Zhou

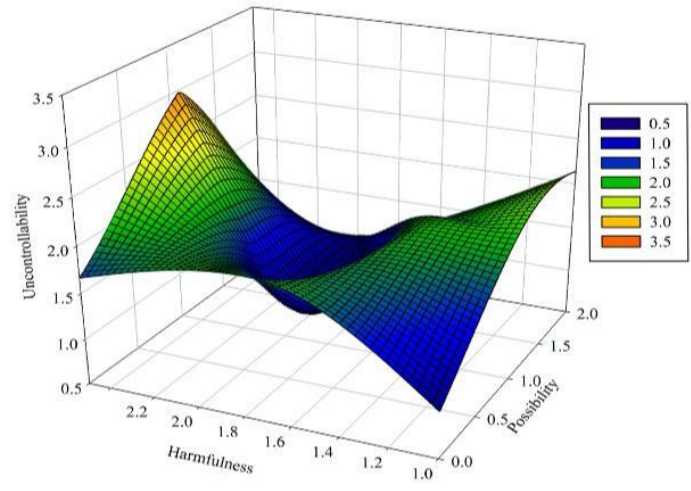

c: Historical

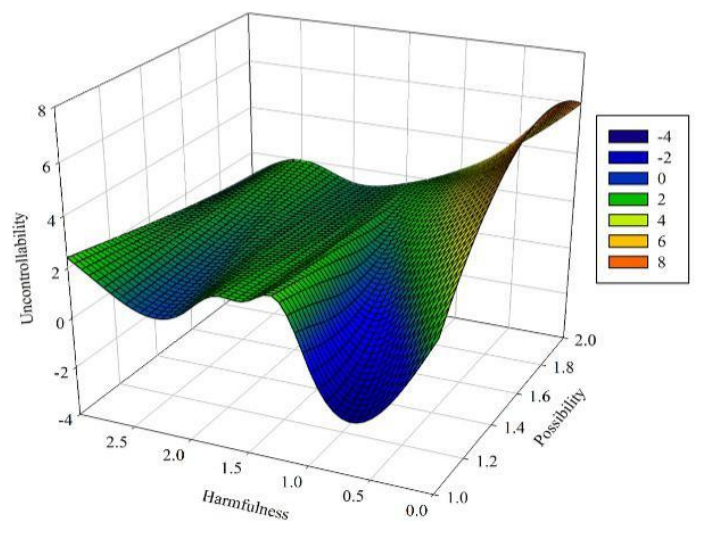

d: The whole of Hongshan District

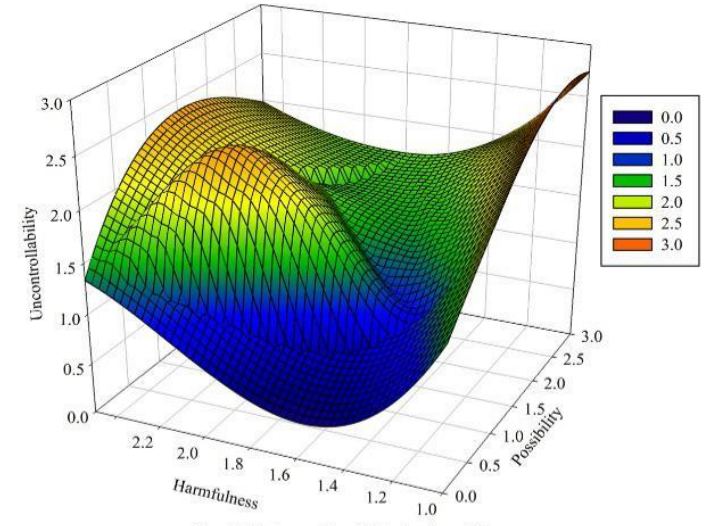

b: Existing Snail-Pak sha Chau

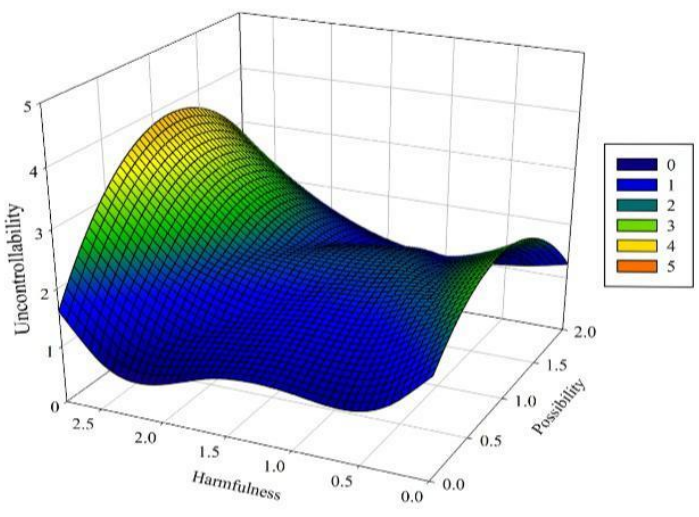

d: Emergency Monitoring Point

Figure4 Three dimensional risk matrix diagram of Wuhan City 


\section{Discussion}

Schistosomiasis is an important water infectious disease. Although it is in a low epidemic state all over the world, some areas still belong to schistosomiasis epidemic areas [26]. Wuhan used to be a schistosomiasis epidemic area. In this study, we investigated the distribution of snails in Wuhan city in 2020, and found that the area of snails and the density of snails in Tianxiingzhou, the existing snail sites in Hongshan district, increased significantly in 2020. This is consistent with the study of Zhou xiaonong et al. [27] on the influence of floods in the Yangtze River Basin on the transmission of schistosoma. In addition, snails were found reviving in historical snails sites. The flood occurred in Wuhan section of the Yangtze River in 2020, which made the whole flood area immersed in the flood for a long time. However, snails are easy to grow and reproduce in the environment with suitable humidity and vegetation. The rise and fall of flood provided an appropriate environment for the growth and reproduction of snails, and flood coverage promoted the development and hatching of snails eggs [28]. This is similar to the research results of Zhou Xiaonong et al. [29], indicating that severe floods will increase the diffusion range and degree of snails, and even cause the migration of snails attached to suspended solids. Although flood disasters will have an impact on the prevention and control of schistosomiasis, the impact seems to be lower than that of COVID-19. Wuhan city also suffered from floods in 2019, but the average density of live snails was significantly lower than in $2018\left(0.0167 / 0.11 \mathrm{~m}^{2} \mathrm{VS}\right.$ 0.0172/0.11 $\mathrm{m}^{2}$ ) in Tianxingzhou, which there was not COVID-19 epidemic in 2019. It further proves that the flood disaster may not be the reason for the increase in the density of snails, but the rapid increase in the density of snails due to the impact of the new coronavirus pneumonia in Wuhan.

Studies have shown that risk assessment specialists are highly motivated, with an average of more than twenty years of experience in schistosomiasis control. Theoretical research shows that the expert authority coefficient of the evaluation index is greater than 0.7 , which indicates that the expert evaluation has credibility and persuasion [22]. The results showed that the experts were familiar with schistosomiasis control, and they were the authoritative experts in this field. The adjusted Kaiser model results show that 
the risk value of the north bank outside Tianxingzhou dike is the largest, followed by the whole Tianxingzhou, and the whole risk value of Hongshan district ranks the third. Due to the kaiser evaluation system, the whole Hongshan district, Tianxingzhou, historical snail and Pak sha Chau will be independently evaluated by experts. The overall risk value of Tianxingzhou is not obtained by the weighted average of all parts of Tianxingzhou, so it is in accordance with the actual situation that the risk value of Tianxingzhou is higher than the overall risk value of Tianxingzhou. The results show that experts empower $21 \%$ of the public opinion influence index, highlighting the consensus of experts on the importance of public opinion influence after the occurrence of acute infectious diseases. In the novel coronavirus public health emergency, the blind orientation of public opinion in the early stage caused serious difficulties to the control of infectious diseases in the late stage [30]. With the rapid development of the network, bad information can spread and ferment rapidly on the network, resulting in exaggerated or false publicity, which will cause difficulties and harm to the late prevention and control of schistosomiasis. In the adjusted Kaiser model, expert weight is introduced to give weight to experts for each dimension index, which makes full use of the experience and knowledge of experts. The evaluation results have more practical significance .

The two-dimensional risk matrix shows that the North Bank of Tianxing zhou North Shore belongs to high-risk area, Hongshan district as a whole, Tianxingzhou and end of the continent of Tianxingzhou belong to medium risk area. However, other risk events belong to low-risk or negligible area. The three dimensional risk matrix shows that the potential risk level of the existing snail spot Tianxingzhou is high, which the possibility of risk events is high. The whole Hongshan district shows that the risk event is serious, and the possibility of the risk event is proved from the quantitative and qualitative perspectives. The two-dimensional risk matrix and the three-dimensional risk matrix show the occurrence level of each risk event in Wuhan city from the plane and three-dimensional perspectives respectively, which is consistent. The results obtained by the above three methods are basically consistent, which mutually verify the reliability and credibility of the expert evaluation results. 
The limitations of this study mainly lie in the strict requirements of the expert consultation method, the complex content, many evaluation indicators, and the long time spent by experts, which may lead to deviation of the evaluation results. All the invited experts are senior experts in the field of public health. There is a lack of experts related to clinical treatment of schistosomiasis, and the evaluation results may be biased [31].

\section{Conclusions}

The density of snails increased under in the influence of Covid-19, which the risk of schistosomiasis outbreak in Wuhan increased. Hongshan district as a whole, existing snail site Tianxingzhou, and existing snail site outside the north bank of Tianxingzhou were the places with the highest risk of schistosomiasis infection. Moreover, the recurrence of historical snails increases the risk of schistosomiasis outbreak in Wuhan. At the later stage of the epidemic, Wuhan city should strengthen the prevention and control of schistosomiasis infection, strengthen the inspection and control of historical snail sites, and promote the health education of schistosomiasis.

\section{Additional files}

Additional files 1: Table1 Comparative analysis of snail situation in WuHan City from 2018 to 2020. (EXCLE 10kb)

Additional files 2: Table2 Distribution of population characteristics at each snail point in WuHan City. (EXCLE 11kb)

Additional files 3: Table4 Evaluation Index System. (EXCLE 11kb)

Additional files 4: Table6 the risk value of the adjust Kasier model. (EXCLE 11kb)

\section{Abbreviations:}

COVID-19: Coronavirus disease 2019;

\section{Acknowlesgements}

The authors would like to thank the staff of the Hongshan and Jianan district of Schistosomiasis Control and Prevention for their hard work in data collection. The authors would also like to thank schistosomiasis specialist of Wuhan Center for Disease Control and Prevention who given advice. Editors and reviewers are thanked for their 
valuable comments.

\section{Funding}

This study was financially supported by China Association for Science and Technology (grant No. 20200608CG111306).

\section{Availability of data and materials}

Raw datasets generated during the study are available from the corresponding author, when provide legitimate scientific investigators to use the data by written request.

\section{Authors' contributions}

T-XD, L-GM and X-DD designed the study. H-YF, Z-LJ, D-XA, Z-L, S-C and X-YF collected the data. L-GM, X-MX and T-XD performed the statistical analyses. L-GM, T-XD and X-DD revised and finalized the manuscript. All authors read and approved the final version of the manuscript.

\section{Competing interests}

No conflict of interest.

\section{Consent for publication}

All authors provided consent for publication.

\section{Ethics approval and consent to participate}

Not applicable.

\section{Author details}

1 School of Health Sciences, Wuhan University, Wuhan 430072, China;

2 Wuhan Hongshan Center for Disease Control and Prevention, Wuhan 430070, China;

3 Wuhan Jiangan Center for Disease Control and Prevention, Wuhan 430014, China;

4 Wuhan for Disease Control and Prevention, Wuhan 430000, China;

\section{Reference}

1. Sun, L.-P., W. Wang, Q.-B. Hong, S.-Z. Li, et al. Approaches being used in the national schistosomiasis elimination programme in China: a review. Infectious diseases of poverty. $2017 ; \mathbf{6}(1): 1-9$.

2. Schistosomiasis. [cited 2020 2,5]; Available from: https://www.who.int/en/news-room/fact-sheets/detail/schistosomiasis. Accessed 5 February 2020.(In United States)

3. Gordon, C.A., J. Kurscheid, G.M. Williams, A.C. Clements, et al. Asian 
schistosomiasis: current status and prospects for control leading to elimination. Tropical medicine and infectious disease. 2019; 4(1):40.

4. Molehin, A.J. Schistosomiasis vaccine development: update on human clinical trials. Journal of biomedical science. 2020; 27(1):28.

5. Colley, D.G., A.L. Bustinduy, W.E. Secor, and C.H. King. Human schistosomiasis. The Lancet. 2014; 383(9936):2253-2264.

6. Becker, J.M., A.A. Ganatra, F. Kandie, L. Mühlbauer, et al. Pesticide pollution in freshwater paves the way for schistosomiasis transmission. Scientific Reports. 2020; 10(1):3650.

7. Zhang, Y., Y. Xie, Q. Chen, X. Chen, et al. Prevalence and co-infection of schistosomiasis/hepatitis B among rural populations in endemic areas in Hubei, China. Transactions of the Royal Society of Tropical Medicine and Hygiene. 2020; 114(3):155-161.

8. Chen, Y.-Y., X.-B. Huang, Y. Xiao, Y. Jiang, et al. Spatial analysis of schistosomiasis in Hubei Province, China: a GIS-based analysis of schistosomiasis from 2009 to 2013. PLoS One. 2015; 10(4):0118362.

9. Yang, G., P. Vounatsou, X. Zhou, M. Tanner, and J. Utzinger.A potential impact of climate change and water resource development on the transmission of Schistosoma japonicum in China. Parassitologia. 2005; 47(1):127-134.

10. Chao Tang, C.Z., Changhao He,Zhenzuo Zhou. Sociological investigation on a large-scale outbreak of acute schistosomiasis in Wuhan. Chinese Journal of pathogenic biology. 1991; 004(001):4-8. (In Chinese)

11. Wang Yan, H.S.X., Hu Lai Lin, et al. Analysis of acute schistosomiasis in Wuhan from 1991 to 2000. Chinese Journal of schistosomiasis control. 2002; 14(3):212212. (In Chinese)

12. Yao Q, X.M., Zhou DJ, et al. Report on emergency management of an outbreak of schistosomiasis in central Wuhan Chinese Journal of Schistosomiasis Control. 2006; 18(1):70-71.

13. Chen, S., Z. Zhang, J. Yang, J. Wang, et al. Fangcang shelter hospitals: a novel concept for responding to public health emergencies. The Lancet. 2020; 395(10232):1305-1314.

14. Leung, K., J.T. Wu, D. Liu, and G.M. Leung. First-wave COVID-19 transmissibility and severity in China outside Hubei after control measures, and second-wave scenario planning: a modelling impact assessment. The Lancet. 2020; 395(10233):1382-1393.

15. Allan, F., S.M. Ame, Y.-N.T. Tian-Bi, B.V. Hofkin, et al. Snail-related contributions from the Schistosomiasis Consortium for Operational Research and Evaluation program including xenomonitoring, focal mollusciciding, biological control, and modeling. The American journal of tropical medicine and hygiene. 2020; 103(1_Suppl):66-79.

16. Crawford, M. and G. Wright. Delphi Method. 2016;1-6.

17. Varndell, W., M. Fry, M. Lutze, and D. Elliott. Use of the Delphi method to generate guidance in emergency nursing practice: A systematic review. International emergency nursing. 2020:100867. 
18. Guppy, K.H., J. Harris, J.A. Bernbeck, and H.S. Brara. Impact of Quality Assessment on Clinical Practice, Kaiser Permanente, in Quality Spine Care. Springer. 2019;315-339.

19. Maskin, E. Arrow's IIA Condition, May's Axioms, and the Borda Count. 2020.

20. Kong, S., X. Tan, Z. Deng, Y. Xie, et al. Establishment of first engineering specifications for environmental modification to eliminate schistosomiasis epidemic foci in urban areas. Acta tropica. 2017; 172:132-138.

21. He, M.-Z., W. Li, S. Juma, F. Kabole, et al. A Google Earth-based database management for schistosomiasis control in Zanzibar. Geospatial health. 2019; 14(1).

22. Song, H.J., S. Dennis, J.-F. Levesque, and M. Harris. How to implement patient experience surveys and use their findings for service improvement: a qualitative expert consultation study in Australian general practice. Integrated Healthcare Journal. 2020; 2(1):e000033.

23. Song, Y., Z. Chen, S. Zhang, J. Wang, et al. Comprehensive evaluation system of occupational hazard prevention and control in iron and steel enterprises based on a modified Delphi technique. International journal of environmental research and public health. 2020; 17(2):667.

24. Zheng, J., L. Lou, Y. Xie, S. Chen, et al. Model construction of medical endoscope service evaluation system-based on the analysis of Delphi method. BMC Health Services Research. 2020; 20(1):1-13.

25. Hazards Vulnerability Analysis. Available from: https://www.calhospitalprepare.org/hazard-vulnerability-analysis. Access on 5 February 2020.(In United States)

26. Lackey, E.K. and S. Horrall. Schistosomiasis (Schistosoma Haematobium). StatPearls [Internet]. 2020.

27. Wu, X.-H., S.-Q. Zhang, X.-J. Xu, Y.-X. Huang, et al. Effect of floods on the transmission of schistosomiasis in the Yangtze River valley, People's Republic of China. Parasitology International. 2008; 57(3):271-276.

28. Zhang, S., T. Wang, Y. Zhou, Z. Cao, et al. Influence of the Three Gorges Dam on schistosomiasis control in the middle and lower reaches of the Yangtze River. Global Health Journal. 2019; 3(1):9-15.

29. Cao, C., L. Shizhu, and X. Zhou. Impact of schistosomiasis transmission by catastrophic flood damage and emergency response in China. Chinese Journal of Schistosomiasis Control. 2016; 28(6):618-623.(In Chinese)

30. Rawson, T., C. Huntingford, and M. Bonsall. Temporary'circuit breaker'lockdowns could effectively delay a COVID-19 second wave infection peak to early spring. Frontiers in Public Health. 2020; 8:899.

31. Humphrey-Murto, S. and M. de Wit.The Delphi method-more research please. Journal of clinical epidemiology. 2019; 106:136-139. 


\section{Figures}

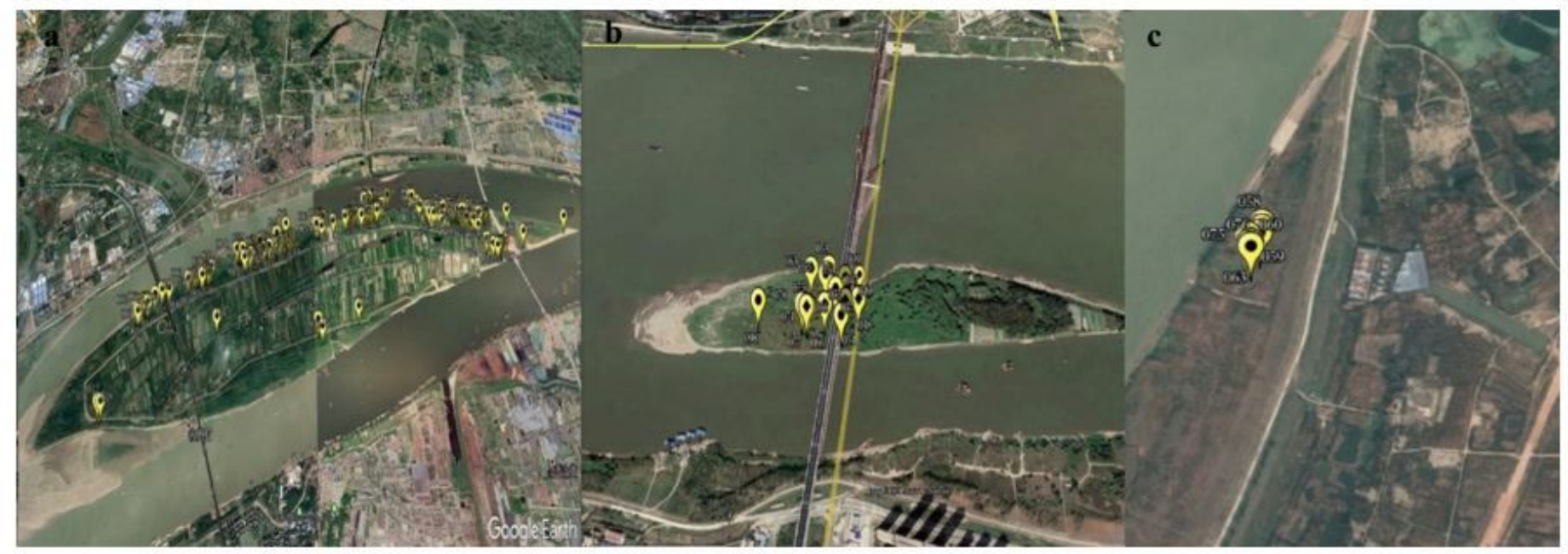

\section{Figure 1}

Distribution of snails in Wuhan city in 2020. a:express Tianxingzhou, b:express Pak sha Chau, c:express Yangsi Ji village Note: The designations employed and the presentation of the material on this map do not imply the expression of any opinion whatsoever on the part of Research Square concerning the legal status of any country, territory, city or area or of its authorities, or concerning the delimitation of its frontiers or boundaries. This map has been provided by the authors.

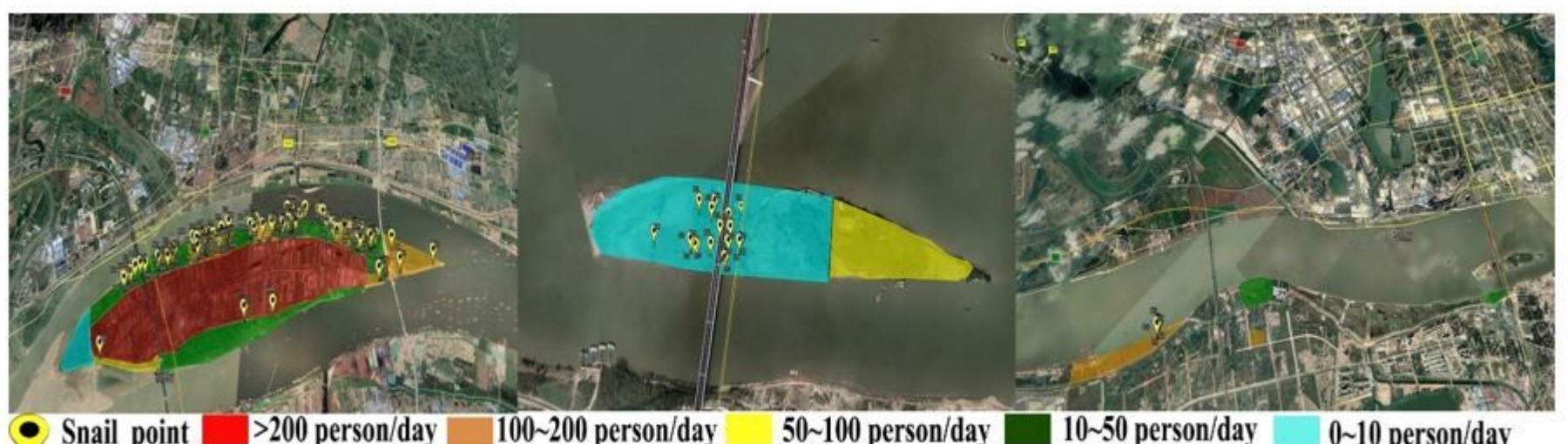

\section{Figure 2}

Schematic diagram of population characteristic distribution and snail point superposition. a:express Tianxingzhou, b:express Pak sha Chau, c:express Yangsi Ji village Note: The designations employed and the presentation of the material on this map do not imply the expression of any opinion whatsoever on the part of Research Square concerning the legal status of any country, territory, city or area or of its 
authorities, or concerning the delimitation of its frontiers or boundaries. This map has been provided by the authors.

\begin{tabular}{|c|c|c|c|c|c|c|}
\hline \multirow{5}{*}{$\begin{array}{l}\text { Possibil } \\
\text { ity }\end{array}$} & $\begin{array}{c}\text { Inevitable } \\
(2.4 \sim)\end{array}$ & & & & & \\
\hline & $\begin{array}{c}\text { Very possible } \\
(1.8 \sim)\end{array}$ & & & D1 & & \\
\hline & $\begin{array}{l}\text { Possible } \\
(1.2 \sim)\end{array}$ & & & $\mathrm{A} / \mathrm{B} / \mathrm{Cl} /$ & & \\
\hline & $\begin{array}{l}\text { Unlikely } \\
(0.6 \sim)\end{array}$ & & & $\begin{array}{c}\mathrm{C} / \mathrm{D} / \mathrm{Al} / \mathrm{B} \\
1 / \mathrm{E} 1 / \mathrm{F} 1 / \mathrm{C} \\
2\end{array}$ & & \\
\hline & $\begin{array}{l}\text { Rare } \\
(0 \sim)\end{array}$ & & $\mathrm{E} / \mathrm{A} 3$ & $\begin{array}{l}\mathrm{A} 2 / \mathrm{B} 2 / \mathrm{D} 2 \\
\mathrm{E} 2 / \mathrm{F} 2 / \mathrm{G} 2\end{array}$ & & \\
\hline \multirow{2}{*}{\multicolumn{2}{|c|}{$\begin{array}{l}\text { Two Dimensional Risk } \\
\text { Matrix }\end{array}$}} & $\begin{array}{c}\text { Negligible } \\
(0 \sim)\end{array}$ & $\begin{array}{r}\text { Low risk } \\
(0.6 \sim)\end{array}$ & $\begin{array}{c}\text { Moderate } \\
(1.2 \sim)\end{array}$ & $\begin{array}{r}\text { Serious } \\
(1.8 \sim) \\
\end{array}$ & $\begin{array}{c}\text { Very serious } \\
\quad(2.4 \sim) \\
\end{array}$ \\
\hline & & \multicolumn{5}{|c|}{ Severity } \\
\hline
\end{tabular}

\section{Figure 3}

Two-dimensional risk matrix diagram of schistosoma control risk events in Hongshan district 


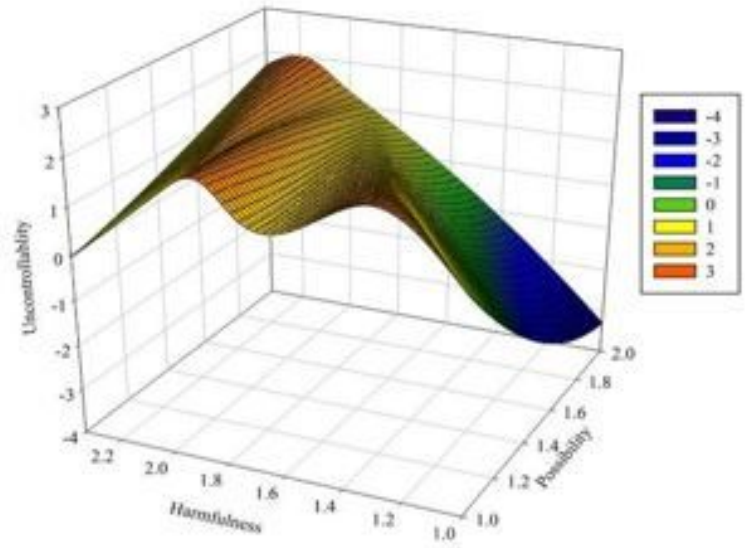

a: Existing Snail-Tianxing Zhou

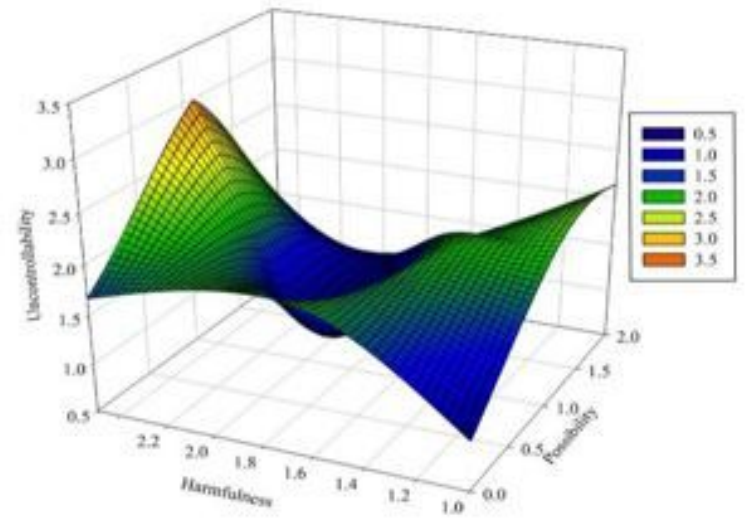

c: Historical

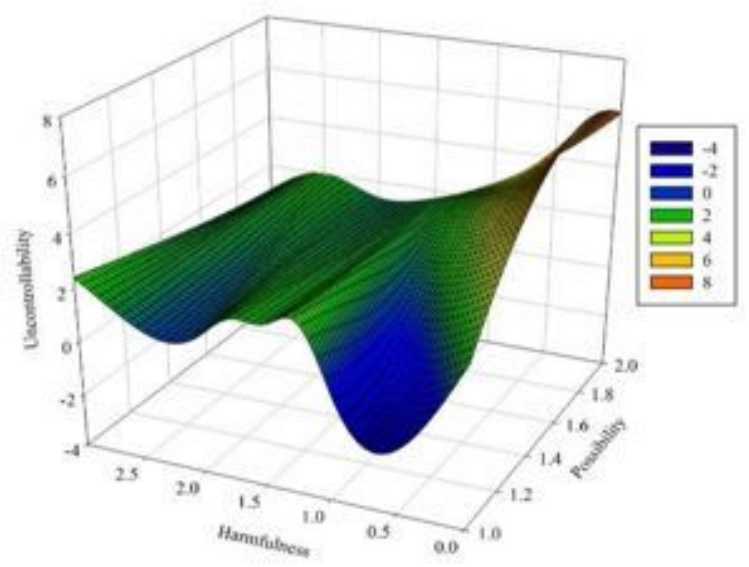

d: The whole of Hongshan District

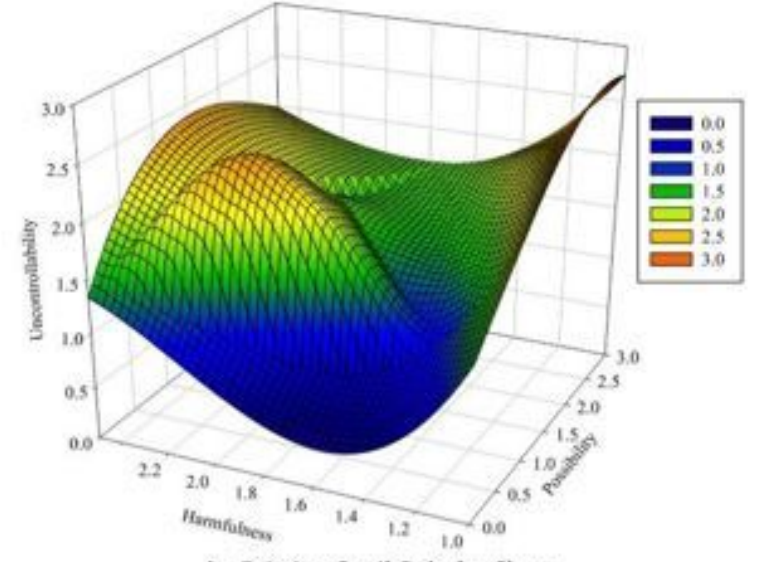

b: Existing Snail-Pak sha Chau

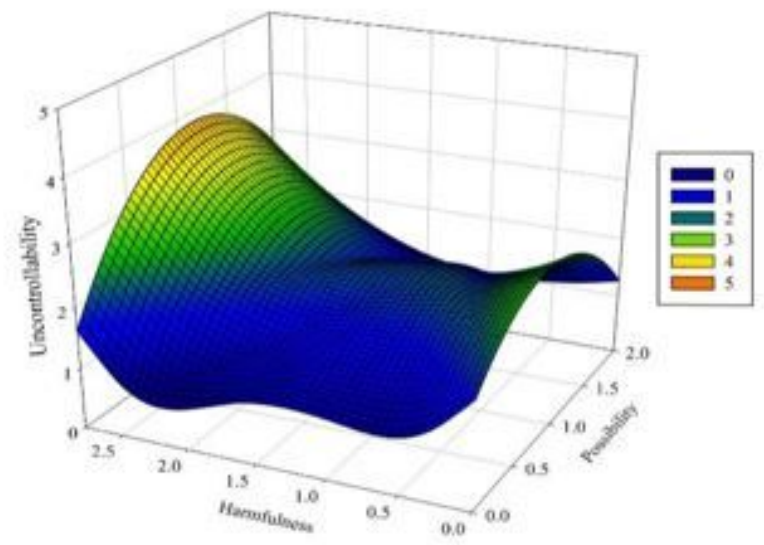

d: Emergency Monitoring Point

\section{Figure 4}

Three dimensional risk matrix diagram of Wuhan City

\section{Supplementary Files}

This is a list of supplementary files associated with this preprint. Click to download. 
- additionalfiles1.xIsx

- additionalfiles2.xIsx

- additionalfiles3.xlsx

- additionalfiles4.xlsx 